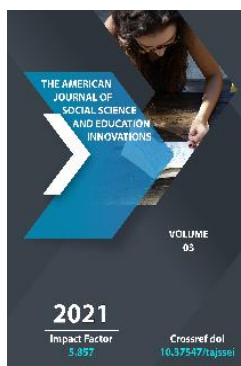

\title{
Lexical Homonyms In Modern English And Uzbek
}

\author{
Tashmatova Madina Abdukarimovna \\ Teacher, “Teaching Languages” Department, “Management In Production” Faculty, Ferghana \\ Polytechnic Institute, Ferghana, Uzbekistan
}

Journal Website:

http://theamericanjour

nals.com/index.php/taj

ssei

Copyright: Original content from this work may be used under the terms of the creative commons attributes 4.0 licence.

\section{ABSTRACT}

Mainly seen in rising interest to learning foreign languages in our state. There has been made many attempts to create new ways and methods of teaching foreign languages. This research is based on language properties of purely English language, and comparative analysis linguistic features between English and Uzbek.

The rising interests to learning foreign require establishing new methods and ways of teaching language. The most effective method of teaching language is considered to find counterparts of language units and expressions from Uzbek language. Besides that it is important to take into consideration special features of national similarities of native language.

\section{KEYWORDS}

Homonyms, homophones, homonyms proper, classification, capital letter.

\section{INTRODUCTION}

The most widely accepted classification is that recognizing homonyms proper, homophones and homographs. Homonyms proper are words identical in pronunciation and spelling, like/as if and liver above or like scale 'one of the thin plates that form the outer covering of most fishes and reptiles' and scale, 'a basis for a system of measuring'. Homophones are words of the same sound but of different spelling and meaning: air :: heir; arms :: alms; buy :: bye : by; him :: hymn; knight :: night; not :: knot; or :: ore :: oar; piece; peace; rain :: 
reign; scent :: cent :: sent; steel :: steal; storey ;: story write :: right :: rite and many others.

For example, in the sentence "The millwright on my right thinks it right that some conventional rite should symbolize the right of every man to write as he pleases." the sound complex [rait] is noun, adjective, adverb and verb, has four different spellings and six different meanings.

The difference may be confined to the use of a capital letter as in bill and Bill, in the following example: "How much is my milk bill?" "Excuse me, Madam, but my name is John." Homographs are words different in sound and in meaning but accidentally identical in spelling: bow [bou] :: bow IbauJ; lead [li:d] :: lead [led]; row [rouj :: row [rau]; sewer l'soua] :: sewer [sjual; tear [tea] :: tear [tia]; wind [wind] :: wind [wand] and many more.

\section{Modern methods of investigating homonyms.}

The intense development of homonymy in the English language is obviously due not to one single factor but to several interrelated causes, such as the monosyllabic character of English and its analytic structure. Inflections have almost disappeared in present-day English and have been superseded by separate words of abstract character (prepositions, auxiliaries, etc.) stating the relations that once expressed by terminations.

The abundance of homonyms is also closely connected with a characteristic feature of the English language as the phonetic unity of word and stem or, in other words, the predominance of forms among the most frequent roots. It is very obvious that the frequency of words stands in some inverse relationship to length, the monosyllabic words will be the most frequent moreover, as the most frequent words are also highly polysemantic, It is only natural that they develop meanings which in the course of time may deviate very far from the central one. When the inter-mediate links fall out, some of these new meanings lose all with the rest of the structure and start a separate existence. Phenomenon is known as disintegration or split of polysemy, Different causes by which homonymy may be brought about subdivided into two main groups:

1) Homonymy through convergent sound development, when or three words of different origin accidentally coincide in sound;

2) Homonymy developed from polysemy through divergent development. Both may be combined with loss of endings and ot Jier morphological processes.

Unlike the homonyms case and sound all the homonyms of the box group due to disintegration or split of polysemy are etymologically connected. The sameness of form is not accidental but based on genetic relationship. They are all derived from one another and are all ul3timately traced to the Latin "buxus". The Concise Oxford Dictionary1) has five separate entries for box:

1. Box n. - 'a kind of small evergreen shrub';

2. Box n. 'receptacle made of wood, cardboard, metal, etc. and usually provided with a lid';

3. Box v. 'to put into a box';

4. Box n. 'slap with the hand on the ear';

5. Box v. 'a sport term meaning 'to fight with fists in padded gloves'.

Homonyms are words different in meaning but identical in sound or spelling, or both in sound and spelling. Homonyms can appear in the language not only as the result of the split of polysemy, but also as the result of leveling of grammar inflexions, when different parts of 
speech become identical in their outer aspect, e.g. «care» from «care» and «care» from "careen». They can be also formed by means of conversion, e.g. "to slim» from «slim», «to water» from «water». They can be formed with the help of the same suffix from the same stem, e.g. «reader» - a person who reads and a book for reading.

Homonyms can also appear in the language accidentally, when two words coincide in their development, e.g. two native words can coincide in their outer aspects: «to bear» from «beran»/to carry/ and «bear» from «bera»/an animal/. A native word and a borrowing can coincide in their outer aspects, e.g. "fair» from Latin «feria» and "fair "from native "fagen" /blond/. Two borrowings can coincide e.g. «base» from the French «base»/Latin basis/ and «base» /low/ from the Latin «bas»/Italian «basso»/.

Homonyms can develop through shortening of different words, e.g. «cab» from «cabriolet», «cabbage», «cabin».

\section{Classifications of homonyms:}

Let us give us the classification of homonyms according to the point of view of famous British lexicologist Walter Skeat1).

A more detailed classification was given by I.V. Arnold. He classified only perfect homonyms and suggested four criteria of their classification: lexical meaning, grammatical meaning, basic forms and paradigms.

According to these criteria I.V. Arnold pointed out the following groups:

a) Homonyms identical in their grammatical meanings, basic forms and paradigms and different in their lexical meanings, e.g. «board» in the meanings "a council» and «a piece of wood sawn thin»;

b) Homonyms identical in their grammatical meanings and basic forms, different in their lexical meanings and paradigms, e.g. to lie - lied - lied, and to lie - lay - lain;

c) Homonyms different in their lexical meanings, grammatical meanings, paradigms, but coinciding in their basic forms,

e.g. «light» | «lights»|, «light» | «lighter», «lightest»/;

d) Homonyms different in their lexical meanings, grammatical meanings, in their basic forms and paradigms, but coinciding in one of the forms of their paradigms, e.g. «a bit» and «bit» (from «to bite»).

The word "polysemy» means «plurality of meanings» it exists only in the language, not in speech. A word which has more than one meaning is called polysemy.

Different meanings of a polysemantic word may come together due to the proximity of notions which they express.

E.g. The word «blanket» has the following meanings: a woolen covering used on beds, a covering for keeping a horse warm, a covering of any kind /a blanket of snow/, covering all or most cases /used attributively/, e.g. we can say «a blanket insurance policy». There are some words in the language which are monosynaptic, such as most terms, /synonym, molecule, bronchitis, some pronouns /this, my, both/, numerals, and so like.

In most cases in the semantic development of a word both ways of semantic development are combined.

Nowadays methods of distinction of homonymy and polysemy were worked out. This helps us to differ the meaning of the 
same word and homonymy which formed in a result of the complete gap of polysemy. Below let us study the methods of studying of synonymy and homonymy.

1. The lexical method of distinction of homonymy and polysemy. This method is concluded in revealing the synonymic connection of polysemy and homonymy. If consonant units are get in one synonymic row when different meanings of words remain still the semantic intimacy and, therefore, it is early to say that polysemy is transferred in to homonymy. If the consonant words are not get in one synonymic row that words are homonymy.

Homonymy and polysemy are different categories in polysemy we deal with the different meanings of the same word. In homonymy we have different words which have their own meanings. For example, the word "man" has ten meanings in Modern English:

1 - shaxs; 2 - erkak kishi; 3 - advakat; 4 matonatli odam;5-odamgarchilik; 6 xizmatkor; 7 - ishchi; 8 - er; 9 - vassal; 10 shaxmat sipohi.

As the all meanings are connected with the major meaning "shaxs". But homonyms are different words which have nothing in common

For example "bark1" - "itning hurishi" and "bark2" - "kema". In this example we can see that homonymy words coincide only in pronunciation and writing.

2. Some scientists say that the substitution of different meanings of words by the synonyms may help to differ the homonyms from polysemantic words. This way of distinction of polysemy and homonymy gets its name in literature as "etiological criterion". For example "voice1 - "sounds uttered in speaking" (sound); "voice2" - "mode of uttering sounds in speaking" (sound); "voice3" "the vibration of the vocal cords in sounds uttered" (sound); "voice4" - "the form of the verb that express the relation of the subject to the action". "Voice1" - "voice2" "voice3" are not homonymic in their character although they have different meanings because of the reason that they can be substituted by the synonymic word "sound". As far as "voice4" is concerned as homonymic to the previous three meanings because the fourth meaning of the word "sound" cannot be substituted by the word common to the previous three meanings of the word "voice" (i.e. the analyzed meaning of the word "sound").

V. Abaev 1) gave etymological criterion of distinguishing homonymic and polysemantic words. He says that homonyms are words which have different sources and only coincided phonetically.

3. We also use the semantic method of distinction of these occurrences. The meaning of homonyms always mutually excepts each other and the meaning of polysemantic words airs formed by one sensible structure keeping the semantic intimacy: one of the meanings assumes, while the other is non-irresistible limit.

The semantic criterion implies that the difference between polysemy and homonymy is actually reduced to the differentiation between related and unrelated meanings. This semantic criterion does not seen to be reliable, firstly, because various meanings of same word and the meanings of two or more 
different words may be equally apprehended by speaker.

It is sometimes argued that the difference between related and unrelated polysemantic words is, as a rule, relatable. It is observed that different meanings have certain stable relationships which are not to be found between the meanings of homonymous words. A clearly perceptible connection of such semantic relationships is commonly found in the meanings of one word and is considered to be indicative to polysemy. It is also suggested that the semantic connection may be described in terms of such features.

For example, we may give the following word

"face1" - 'the front part of human's head".

"face2" - "playing card, building, watches".

In this example we can find that meanings form one sensible structure. Another example shares the same idea:

E.g. The word "fair1" which means "a person with light hairs" and "fairz" which means "just, honest". In this example the meanings except to each other and do not keep the semantic intimacy.

4. There is a fourth method of distinction of polysemy and homonymy. It is morphological method. It means that polysemy and homonymy are characterized by the various word building. So some words which have a few meanings the new word is formed with the same suffix.

For example, for the word "park1" - "place of rest" we form a new word by ending "-ed-": "parked" while in the word "park2" - "a place of keeping automobiles" the new word is formed by "-ing-" ending : "parking".
Typological analysis of homonymy and polysemy in two languages.

Below we would like to compare the English differences between homonymy and polysemy with Uzbek equivalents.

As it was noticed above we have polysemy and homonymy in Uzbek. As in English, in Uzbek homonyms are words identical in sound and spelling but different in meaning.

"o’t1" - "firewood", "o’t2" - "grass" and "o’t" "the verb which means movement".

And another example is from following poem of Khorasmiy:

Bo'ying sarvu sanubardek beling qil1,

Vafo qilg'on kishilarg'a vafo qil2.

"qil1"- noun it is metaphor, "qil2"- verb which express order.

1. In this chapter we partially used the materials of the investigations of Prof. Buranov

As in English, in Uzbek we correspond to polysemantic words the words which have several connected meanings.

For example is "ko'z1" - "a part of human's body" and "ko'zz" - "a sing on wood".

As in, English there is the lexical method of distinction of polysemy and homonymy is used in Uzbek in the same degree.

In Uzbek we have the same phenomenon: For example, the word "dum1" - "a part of animal's body" and "dum2" "a partial comet".

It means that these two meanings we can be substitutive with synonymy "the end of the 
body". It means that these words are polysemantic in their lexical meaning.

If we take another pair of words, e.g. "yoz1" "summer" and "yozz" - 'the form of the verb which expresses the order".

2. Ethimological method can be shown in the following:

Following examples we can find in the Uzbek language as well. For instance, the words "ovoz1" we can substitute into the synonym "sound" while the word "ovozz" in the meaning of "opinion a group of people" is homonymic to the first one, e.g. "yoshlar ovozi".

3. The semantic criterion can also be compared in both two languages.

One example we can find in Uzbek. For instance, the word "bosh1"used in the meaning of "the beginning of human's body" and the word "bosh2" used in the meaning of "the main person in a work, e.g."ishning boshi". These two meanings are alike because they do the same function, so they are not homonymic, they are synonyms.

4. Morphological method of distinction of polysemy and homonymy can also be demonstrated in all the languages compared.

In Uzbek the word "oy1" - e.g. "Yilda o'n ikkita oylar bor" and "oyz" - e.g. "oy - yerning yo'ldoshi" form the new word with the help of the suffix "lik":

Cf.: "Oylik maoshi" and "Bir oylik 14 kundan iborat".

\section{CONCLUSION}

So having analysed the phenomenona of homonymy and polysemy in the two languages we can draw the following conclusion to this chapter: there are no so big differences in these languages in respect to the linguistic phenomena analysed.

However, the following conclusion can also be drawn: the problem of distinction of homonymy and polysemy in all the languages compared has not been investigated thoroughly yet and there is still much opportunities to discover new fields of approaches and this problem is still waiting its salvation.

\section{REFERENCES}

1. A.l. Smirnitsky. (1977). Homonyms in English M. pp.57-59.

2. Buranov, Muminov. (1985). Readings on Modern English Lexicology $\mathrm{T}$. O'qituvchi. pp. 34-47.

3. V.V. Vinogradov. (1977). Leksikologiya I leksikografiya. Izbraniye trudi M. pp. 119-122.

4. E.M. Dubenets. (2004). Modern English Lexicology (Course of Lectures) M. Moscow State Teacher Training University Publishers. pp.1731.

5. Rogova, G. V., \& Vereshchagina, I. N. (1988). Methods of teaching English at the initial stage in high school: A manual for the teacher. M. Education.

6. Hornby. (1974). The Advanced Learner's Dictionary of Current English. Lnd. pp.92-93.

7. I.V, Antrushina., Afanasyev O.V., Morozova N.N. (2019). English lexicology.

8. I.V. Arnold. (1959). Leksikologiya sovremennogo angliyskogo yazika. pp.212-224. 
9. I.V. Arnold. (1986). The English Word. M. High School. pp.143-149.

10. Viktorovna, Z. L., \& Gulimovna, B. G. An International Multidisciplinary Research Journal. An International Multidisciplinary Research Journal, 41(43).

11. Ilmiddinovich, K. S. (2020). Methods Of Teaching English To Young Learners. The American Journal of Social Science and Education Innovations, 2(11), 65-69.

12. Jeremy Harmer. (2001). "How to Teach English" Longman. 